\title{
Forensic Readiness Analysis of CCTV System in Surakarta
}

\author{
Ardymulya Iswardani \\ Duta Bangsa University
}

\author{
Nugroho Arif Sudibyo \\ Duta Bangsa University
}

\begin{abstract}
Aim of this study is to determine the level of forensic readiness in an organization by measuring the DiFRi readiness index. The study was conducted by distributing questionnaires to respondents in the city of Surakarta and then the data was processed using the Guttman scale and the final result was a diffri readiness index. This study concludes in general the forensic readiness of the CCTV system of the city of Surakarta at the ready level.
\end{abstract}

\section{General Terms}

Digital Forensic Readiness, CCTV Systems

\section{Keywords}

Forensic, readiness, guttman, difri, industri 4.0

\section{INTRODUCTION}

The role of CCTV today is needed as a security "insurance" for a community. Its use is considered to have a role as a security mechanism that is currently in great demand, because it is believed to be able to anticipate the onset of crime in a community [1]. Copyright protection conditions against property crime and minimizing the chances of situational crime is a form of CCTV [2], thus the role and function of CCTV is now more than just a tool to monitor the surrounding environment, but also provides a sense of security and trust for someone to a certain degree of owned property or community.

In general, the sequence of recording CCTV images is obtained from cameras that record the sequence of images and store them on DVR (digital video recorders) for further observation at the location of each CCTV system installed. The current CCTV system can be accessed through web browsers or CCTV applications built in to facilitate CCTV system users directly or view recordings stored through remote locations [3].

The ability to record sequences of events and the ability to use them from other locations to display footage from CCTV systems is considered vital for their use by several parties as security guarantees for the protection of assets owned such as property, equipment, equipment to human resources who interact in organizations.

The ability of the CCTV system is beneficial for organizations and law enforcement officials in investigating a criminal event that occurs within an organization. Criminal Investigation is a series of activities aimed at getting answers to the question (who) who committed the crime, (where) where it happened, (what) what happened, (when) when the crime occurred, (why) why the action occurred and (how) how this incident could occur [4].

The $5 \mathrm{~W} 1 \mathrm{H}$ questions are used to build cases both internally and in trials. The five recordings were obtained from evidence of CCTV records owned by the organization or individual.
For investigators or someone appointed to investigate an incident, CCTV recordings have a high value, 9 out of 10 investigators use footage in their work, 1 in 3 investigators find it difficult to investigate issues related to image quality and the scope of CCTV cameras [5].

Image quality problems and the scope of the camera observation area are some of the problems of the CCTV system. The quality of the image itself is influenced by video resolution, camera quality, lighting and the scope of observation [6]. However, the original form of CCTV video files can still be used as evidence. Digital evidence and / or electronic evidence has characteristics that are easily lost, easily damaged and easily changed [7], thus certain mechanisms are needed so that digital evidence and or electronic evidence of CCTV systems can still be used as trial evidence [8].

Volatility is a fundamental characteristic of digital evidence and electronic evidence, thus various mechanisms are needed so that digital evidence and electronic evidence can be maintained both authenticity and integrity. Many mechanisms to maintain the integrity and authenticity of digital evidence and electronic evidence, one of which is by reviewing the readiness of organizations in dealing with incidents involving computer equipment and the transmission of information and electronics. Forensic readiness (forensic readiness) of an organization is currently needed because of the high interaction that occurs both in the internal and external environment. This readiness aims to anticipate or minimize damaged, lost and/or data degradation that can disrupt an organization's business processes [9]

The Digital Forensic Readiness Index (DiFRI) model used in this study aims to evaluate the organization's forensic readiness, the results of the evaluation in the form of an organization index value obtained based on the criteria: 1) strategy; 2) policies and procedures; 3) technology and security; 4) digital forensic response; 5) control and risk; and finally 6) legality [10]. Illustration of DiFRI shown in Figure 1.

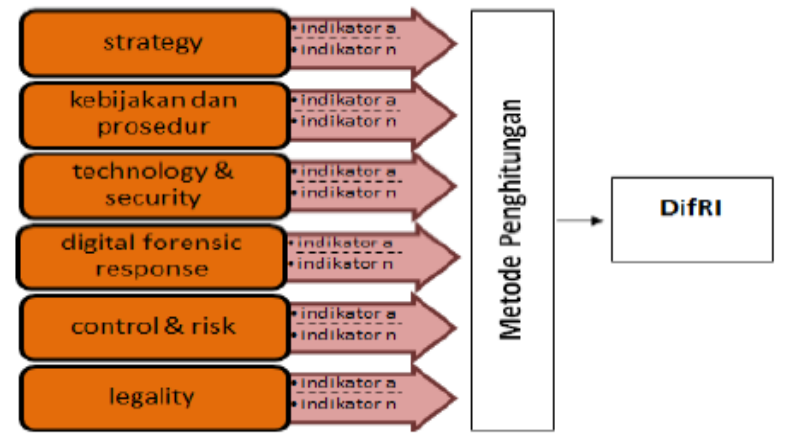

Figure 1. DiFRI 
Figure 1. Showing forensic readiness (forensic readiness) is considered to be used as a reference in improving organizational governance in the future, improving organizational governance is believed to improve organizational performance. The method of calculating the index value in DiFRI uses the Guttman calculation scale, a scale that works expressly obtains "there-no" from respondents through a distributed questionnaire instrument[11] .

The description above explains the importance of organizational readiness in the industrial era 4.0, in summary, industry 4.0 involves a physical cyber system, a system that works asynchronously via the internet in achieving its goals[12].

Based on the explanation above, this study aims to analyze the readiness of forensics in organizations with the DiFRI framework on CCTV systems in the city of Surakarta.

Contributions made to the master plan of business technology research are in the form of the use of CCTV technology for the development of business strategies and innovations by analyzing the readiness of business management based on forensic technology. CCTV is used as a tool for monitoring by security personnel. However, security officers cannot work continuously without stopping. Therefore the role of CCTV as used as monitoring automation is tangible as supporting the role of security officers [13].

CCTV is believed to minimize material and non-material losses. The way CCTV works that can be re-aired in detail causes law enforcement authorities to conduct a forensic analysis if a violation is found at a certain time. The ability of CCTV automation is considered to be able to increase the credibility of the City of Surakarta, in this case the City of Surakarta seeks to create a sense of security and instill a culture of rule of law. The use of CCTV today as part of organizational quality management because of its nature in preventing, identifying, recognizing new patterns that are not yet known[14].

\section{LITERATURE REVIEW}

Good or bad quality video recording CCTV system can be influenced by many things. Laying positions that are difficult to reach, laying positions in open areas[15]. CCTV systems are often damaged or see a decrease in function for various reasons. This is because there is an assumption that the system is durable. Forensic readiness is a method used to evaluate the level of readiness of a system. If there is illegal activity. Wellmanaged system. Considered to have good data quality. Forensic readiness of CCTV systems is needed to determine the level of preparedness of CCTV systems used in the organization's business processes[9]. DiFRI can be used as an effort to prevent the global information age crime that has an impact on organizations, thus the use of this framework is used as a reference to improve performance[11]. Strategy; Policy and Procedure; Technology and Security; Digital Forensic Response; control and risk; and legality in DiFRI is quite complete as a basic criterion in evaluating the performance of an organization's readiness to support investigations from conventional forensics to digital forensics [10]. Organizational ignorance regarding the readiness index can have an impact on organizational performance thus the evaluation of readiness index in this case the forensic readiness serves as a guide for performance improvement [16]

\section{METHOD}

\subsection{Guttman Scale}

The scale used is the Guttman scale, which is a measurement scale with a clear answer, between "yes-no". Furthermore, of the six components above, scoring will be conducted to assess aspects of DiFRI as a whole to determine the Digital Forensic Readiness Index of an organization from the questionnaire and then count the answers to "Yes" and "No", and then an assessment will be carried out on each aspect using formula 1

$$
I_{A}=\frac{\sum_{k=i}^{n} A}{n_{a}} \cdot 10
$$

$I_{A}$ is an index of each aspect, then $A$ is the number of indicators that have a value "there", and $n_{A}$ is the total of indicators in that aspect, while multiplication 10 , is intended to get a scale from 0 to 10 . As for the overall assessment of DiFRI using the formula 2

$$
I_{e l}=\frac{\sum_{k=i}^{n} A e l}{n_{e l}} \cdot 10
$$

IEL is the index of all components, then Ael is the number of indicators that have a value "there", and nel is the total of all indicators, while multiplication 10 , is intended to get a scale from 0 to 10 , or you can also use the formula 3 :

$$
I_{\text {total }}=\frac{\sum_{k=1}^{n} I_{a}}{n_{i a}}
$$

$I_{\text {total }}$ is the overall DiFRI index of components, $I_{A}$ is the index of each component, and $n_{i a}$ is the number of components.

\subsection{DiFRI Indexing}

The DiFRI readiness model aims to provide recommendations and clarify the status of the institution. The institutional readiness scale index is based on DiFRI. Shown Table 2.

Table 2. DiFRI Index

\begin{tabular}{|c|c|c|}
\hline Index & Scale & Description \\
\hline 1 & $8<i \leq$ & Very Ready \\
\hline 2 & $6<i \leq$ & Ready \\
\hline 3 & $4<i \leq$ & Quite ready \\
\hline 4 & $2<i \leq$ & Less Ready \\
\hline 5 & $0<i \leq$ & Not Ready \\
\hline
\end{tabular}

Table 2 explains the readiness index value is less than 2 (two) not ready until the value is ready if the readiness index value is less than equal to 10 (ten).

\section{RESULT}

Forensic readiness analysis in the Surakarta City CCTV system found that the digital CCTV forensic readiness level in Surakarta City was in the index of 7.26 (Very Ready). The digital CCTV forensic readiness level of Surakarta City is shown in table 1 .

Table 1 Difri Index

\begin{tabular}{|c|c|c|}
\hline No & Components & Indeks \\
\hline 1 & Strategy & 8,17 \\
\hline 2 & Policy and Procedure & 7,33 \\
\hline 3 & Technology and Security & 7,29 \\
\hline 4 & Digital Forensic Response & 7,14 \\
\hline 5 & Control and Risk & 6,72 \\
\hline 6 & Legality & 6,93 \\
\hline \multicolumn{2}{|c|}{ DiFRI } & 7,26 \\
\hline
\end{tabular}


The table shows the level of digital CCTV forensic readiness of Surakarta City which is generally at the ready level.

Questionnaire data collection was carried out with online entries distributed to several populations representing several government agencies and the community with a total of 30 respondents. The time span of data collection is from 1 November 2019 to 30 November 2019. After testing the validity and reliability, it can be seen that all instruments are declared valid and reliable.

Forensic readiness component with Dif in the strategy component is worth 8.17 , showing the highest index value or very ready. This shows the awareness of the management of CCTV in the city of Surakarta of the importance of digital forensic readiness. This forensic readiness aims to facilitate the collection of data and incident handling. This strategy is supported by the readiness of the policy and procedure components with a value of 7.33 or very ready. Policies and procedures represent the seriousness or commitment of the organization in handling CCTV systems that are managed. In the technology and security component with a readiness index value of 7.29. shows the use of the latest technology applied in the city of Surakarta to create a safe condition with the use of CCTV systems that operate for 24 hours to monitor activities that occur in the city of Surakarta. The Digital Forensic Response component is at level 7.14 very ready. The index value shows the readiness of the members of the Surakarta City CCTV management who are swift in handling reports of incidents that occur in the Surakarta City area which are reported by the public. The level of forensic readiness in the CCTV in Surakarta City shows the same thing in the Control and Risk and Legality components, each worth 6.72 and 6.93 , both of which indicate the level of readiness ready.

The readiness of the Surakarta City CCTV analyzed by the DiFRI framework shows the importance of an institution to conduct periodic self-evaluations for work programs that are managed primarily for digital forensic readiness.

This readiness is intended so that in the future an incident involving CCTV will occur. Evidence and witnesses and the handling of the crime scene can be preserved in its integrity and authenticity.

\section{CONCLUSION}

Based on the findings that have been obtained during the research process. Organizations that carry out routine evaluations of the managed system or the managed CCTV system in Surakarta. The organization is considered capable of handling when an incident involves or requires the use of recordings from a CCTV system that is owned.

\section{ACKNOWLEDGMENTS}

Thanks to People of Surakarta, Government and Duta Bangsa University for supporting the research of Forensic Analysis using DiFRI in CCTV System of Surakarta.

\section{REFERENCES}

[1] J. T. Cho and J. Park, "Exploring the effects of CCTV upon fear of crime: A multi-level approach in Seoul," Int. J. Law, Crime Justice, vol. 49, pp. 35-45, 2017.

[2] Y. Jang, D. Kim, J. Park, and D. Kim, "Conditional effects of open-street closed-circuit television (CCTV) on crime: A case from Korea," Int. J. Law, Crime Justice, vol. 53, no. November 2017, pp. 9-24, 2018.

[3] J. Wickes, "CCTV: an open door into enterprise and national infrastructure," Netw. Secur., vol. 2018, no. 2, pp. 5-8, 2018.

[4] M. P. J. Ashby, "The Value of CCTV Surveillance Cameras as an Investigative Tool: An Empirical Analysis," pp. 441-459, 2017.

[5] C. Dowling, A. Morgan, A. Gannoni, and P. Jorna, "How do police use CCTV footage in criminal investigations?," Trends issues crime Crim. justice, no. 575, 2019.

[6] H. Khanafi and S. E. Wahyuningsih, "Recording of Circuit Television ( CCTV ) as Evidence in The Process of Evidence on Criminal Case in Indonesia," vol. 1, no. 3, pp. 737-742, 2018.

[7] M. N. Al-Azhar, Digital Forensic: Panduan Praktis Investigasi Komputer. Salemba Infotek, 2012.

[8] ACPO, "ACPO Good Practice Guide for Digital Evidence," ACPO, no. March. 2012.

[9] S. Park et al., "A comparative study on data protection legislations and government standards to implement Digital Forensic Readiness as mandatory requirement," Digit. Investig., vol. 24, pp. S93-S100, 2018.

[10] T. Widodo and Y. Prayudi, "Model Digital Forensic Readiness Index ( Difri ) Untuk Mengukur Tigkat Kesiapan Institusi," 2013.

[11] T. Widodo, "Pengembangan Model Digital Forensic Readiness Index (DiFRI) Untuk Mencegah Kejahatan Dunia Maya,” J. Inform. Sunan Kalijaga, vol. 1, no. 1, pp. 41-46, 2016.

[12] Wikipedia, "Industri 4.0," Wikipedia, 2019. [Online]. Available: https://id.wikipedia.org/wiki/Industri_4.0.

[13] D. Seckiner, X. Mallett, C. Roux, D. Meuwly, and P. Maynard, "Forensic image analysis - CCTV distortion and artefacts," Forensic Sci. Int., vol. 285, pp. 77-85, 2018.

[14] M. Elyas, A. Ahmad, S. B. Maynard, and A. Lonie, "Digital forensic readiness: Expert perspectives on a theoretical framework," Comput. Secur., vol. 52, pp. 7089, 2015.

[15] Y. Prayudi, "Digital Forensics Readiness," catatanforensikadigital, 2013. [Online]. Available: https://catatanforensikadigital.wordpress.com/2013/11/13 /digital-forensics-readiness/.

[16] S. Statistik, “Skala Guttman,” 2016. [Online]. Available: https://www.spssstatistik.com/kuesioner-penelitiandengan-skala-guttman/. 